\title{
Changing the sources and usage of energy for a better and sustainable future for all: Proceedings from the 2021- 2022 High School Big Data Challenge
}

\author{
Under the patronage of Canadian Commission for UNESCO
}

STEM Fellowship's High School Big Data Challenge is an inquiry-driven experiential learning program that provides students an opportunity to learn and apply the fundamentals of data science - a crucial skill set for a young researcher in the digital age - through independent research projects. The COVID-19 pandemic disrupted high school education, at the same time creating a "fertile ground" for interdisciplinary, student-driven STEM education.

This year, we invited students to explore issues of Affordable and Clean Energy at the Individual and Community Levels and to suggest their own evidence-based solutions, using Open Data and the principles of Open Science. Students explored many topics, ranging from Greenhouse Gas Emissions of School Buses to Legitimacy of Electric Vehicles to be the Greener Alternative

We developed in-depth learning modules designed to bridge the gap between traditional high school courseware and digital reality and computational science. The students learnt a broad range of data analytics tools and programming languages which are useful for uncovering hidden patterns, trends in structured and unstructured data. Some of the tools the students learnt and used include Python, R, LaTeX, and machine learning.

On behalf of the STEM Fellowship, we extend our sincere congratulations to all students who participated in the challenge, and wish them the best for their future endeavours. We want to express our appreciation to all the mentors and volunteers. This program would not be possible without patronage of CC UNESCO and generous support of our sponsors: RBC Future Launch, Let's Talk Science, Digital Science, Infor, SCWST, CISCO Networking Academy, Canadian Science Publishing, and the University of Calgary Hunter Hub for Entrepreneurial Thinking.

It has been a privilege for us to witness the analytical capabilities of the data-native generation of students first hand, and we are certain all entrants will continue to demonstrate excellence in their respective academic and professional careers.

\section{Zackary Masri}

Chief Data Officer

\section{Dr. Sacha Noukhovitch}

Founder, President and Editor-in-Chief

\section{Disclaimer}

These abstracts are provided for all student teams that have submitted project reports by February 1, 2022. The STEM Fellowship Journal editorial board has made every effort to ensure proof and English editing of these abstracts in a limited amount of time, and neither organization as a whole or any of its volunteer members can be held accountable for inaccuracies that may have occurred in the abstract publication. Abstracts are published in no particular order. 


\section{Using genetic algorithms to optimize energy harvesting relative to budgets and geolocation}

\section{Andrei Dumitrache ${ }^{1}$ and Alex Rodriguez-Perez ${ }^{1}$}

\section{Salmon Arm Secondary School, British Columbia, Canada}

Replacing non-renewable energy sources with clean energy sources is one of the key steps in addressing the climate change crisis. Chapter 5 of the UN's Energy Progress Report shows us that money is less of a concern as wealthier countries work together to support poverty-stricken countries in affording this transition to renewable energy. That being the case, a new, more challenging problem arises: how should a country make the most of a budget when purchasing energy harvesting technologies? This paper presents the solution to this problem through the application of genetic algorithms and reinforced learning to budgets and locations. In our research, we worked towards developing a method in the form of an algorithm that takes the name of a country along with a budget and returns the quantities of solar panels, wind turbines, and point absorbers that would generate the most $\mathrm{kWh} /$ day. With modified genetic algorithms, days of analyzing their performances along with results, and databases containing up to 70 years of data recorded hourly, our paper presents a method that can be used to bring about a new generation of data that could lead to possible improvements within government plans to include clean energy sources in their energy mix, should they be applied. An app has also been developed, giving anyone the ability to use our algorithm by simply inputting any country and budget, as climate change is a problem that affects us all, therefore our data should be available to everyone.

\section{A novel method for predicting photovoltaic potential in Canada}

\author{
Abel Diress ${ }^{1}$, Bilal Shaikh1, and Ria Patel ${ }^{1}$ \\ ${ }^{1}$ Merivale High School, Ontario, Canada
}

To mitigate the effects of global climate change caused by fossil fuel emissions, Canada needs to reach net-zero emissions as soon as possible. But for a country that relies heavily on nonrenewable resources to heat homes, fuel transportation and support industry, the renewable alternative must be reliable, efficient, and effective. One of the front-runners in sustainable energy solutions is solar power, and in a country as vast as Canada, it is sure to yield promising results. Our team analyzed the photovoltaic (PV) potential of different geographical sites across the country using data from the Canadian Weather Energy and Engineering Datasets (CWEEDS). Using K-means clustering, an unsupervised machine learning model, we placed all 564 locations into 5 clusters, and then predicted the PV potential for each cluster using a range of imminence and radiation variables. Through plotting our results on scatter graphs, we found the PV potential in most of Canada is much higher than the world average (4.11-6.96 $\mathrm{kWh} / \mathrm{m}^{2}$ ). Furthermore, the province of Alberta known for its tar sands and oil production has the highest PV potential in the country, so the province has the potential to become the leader in solar energy production in Canada. These findings can aid provincial and municipal governments in optimizing their shift towards solar power and other renewable energy sources to maximize output. By identifying solar power as a strong alternative to fossil fuels, administrations can now start working towards setting up solar farms in places where they would optimally serve Canadians and take the first step to decrease our national carbon footprint.

\section{Examining the impact on the economy when $100 \%$ clean energy is implemented in Ontario}

\section{Zainab Majid ${ }^{1}$ and Raifah Rahman² \\ ' John G. Diefenbaker High School, Alberta, Canada \\ ${ }^{2}$ Hurlstone Agricultural High School, NSW, Australia}

Finding ways to incorporate renewable energy into our lives and examining the impacts it will have is essential to understanding the importance of renewable energy in our lives. We chose to examine the effect on the economy after im plementing $100 \%$ renewable energy in Ontario due to the wide variety of data available to analyze, and the plethora of information available about its energy uses. To reach our conclusion, we used a variety of resources: Statistics Canada and the Ontario Data Catalog (open source data), Microsoft Excel, Python (Mat plotlib/Seaborn and MatLab) to compile and present our data. From our data, it shows the Ontario government in Canada has been building 
up the grid generation capacity for renewable energy by developing new renewable energy sites and technologies before attempting to actively generate renewable energy. Also, the implementations created several jobs before the pandemic. From current circumstances, we can infer that the pandemic resulted in a massive loss of jobs. As the infrastructure for renewable energy sources continues to grow, it is unclear whether clean energy is assisting in the recovery of the economy from the pandemic. To conclude, we found that renewable energy introduces new challenges for Ontario's economy, especially with challenges such as the COVID-19 pandemic, but the government continues to grow the use of clean energy technologies in spite of the pandemic. Continuing this research, we would recommend looking into the effect on agriculture and the environment as a result of implementing clean energy procedures in Ontario.

\section{Multifaceted factors influencing worldwide renewable and affordable energy development}

Xian Jun Tsang ${ }^{1}$, Kwan To Chuii ${ }^{1}$, Cho Lok Ng${ }^{1}$, and Tai Hang Chan ${ }^{1}$

\section{${ }^{1}$ Pui Ching Middle School, Hong Kong}

Transitioning to affordable, clean, and sustainable energy for people and communities is of paramount importance for sustainable economic expansion and urban encroachment. In depth and comprehensive understanding with multifaceted analysis into the challenges faced by governments and private enterprises is necessary to upgrade our energy structure. This paper examines the correlation between the share of renewable energy in various countries and hypothesized factors using linear regression and multiple linear regression, encompassing 1) the averaged GDP of each country, 2) the average GDP change of each country, 3) the energy consumption size of each country, 4) the average cost of renewable energy sources and 5) the cost of each renewable energy source. The results show that the first three factors examined have no significant correlation with increasing the share of renewable energy in the global fuel mix, while the last one - the average cost of renewable energy sources has a correlation with the continuous increase in global renewable energy consumption.Thus, in order to accomplish Sustainable Development Goal 7 (SDG7) in the 2030 Agenda for Sustainable
Development, it is suggested that capitalizing on the global energy transformation to support achievement of SDG7 requires greater levels of direct research and development investments into improving energy technologies to lower its costs, providing economic incentives for governments and private corporations to pledge to use more renewable energy in processes like resource extraction, manufacturing, logistics and more to come, to ultimately increase coordination and enhance synergies.

\section{Investigating existing wind turbine fleet and modeling optimal geographic locations for future wind farms in southern Ontario}

Andrew Kang ${ }^{1}$, Liam Morrison ${ }^{1}$, Henry Sun ${ }^{1}$, and Andy Tang ${ }^{1}$

\section{${ }^{1}$ Hillfield Strathallan College, Ontario, Canada}

Wind power, given its abundant, low-carbon, and low-cost nature, has become the most promising source of renewable energy in Canada. Ontario, the leader of wind production in Canada, has already successfully harnessed wind power to meet on average $8 \%$ of its annual electricity demand, and this is expected to continue to increase over time. The Ontario wind turbine fleet is primarily concentrated in southern Ontario. This study aims to investigate the profile and performance of the existing wind turbine fleet in southern Ontario as well as identify optimal geographical locations for future wind farm development in this region. Recent and historical data, including wind power available capacity, wind power output, electricity demand, geographic locations, and key technical configurations were collected from the Ontario Independent Electricity System Operator (IESO) and the Canadian Wind Turbine Database. Data for climatological factors were collected from the Copernicus Climate Change Service. A broad analysis of the Ontario wind turbine fleet was first conducted. The profile and performance of the entire fleet in southern Ontario was presented to guide shortterm and long-term planning. A thorough examination of seven sample wind farms in southern Ontario was conducted to identify the turbine fleet's strengths and possible areas of improvement. Further, machine learning models were developed and trained to suggest seven optimal geographic locations for future wind farm initiatives across southern 
Ontario.

\section{Investigating the feasibility of implementing a tidal generator in Yakutat, Alaska}

\section{Antonio Kappos ${ }^{1}$, Leean Xu ${ }^{1}$, Natasa Sormaz ${ }^{1}$, and Nicole Grace ${ }^{1}$}

\section{${ }^{1}$ Hillfield Strathallan College, Ontario, Canada}

The objective of this study was to determine how a tidal energy barrage could be implemented as a cleaner energy source in Yakutat, Alaska. Tidal energy has been extensively researched as a less costly alternative for the local community. Furthermore, the largest tidal power generator in the world, the Sihwa Tidal power plant, was used as a template for the potential energy output and logistics of the project. Lake Sihwa, where the tidal power station resides, is a manmade lake located off the shore of Incheon. The study was conducted using wave height data collected from Yakutat Bay as well as Gyeonggi Bay, which borders the Sihwa Tidal power plant. The data obtained was retrieved from the Permanent Service for Mean Sea Level (PSMSL). This study looks at the economic viability of constructing such a tidal plant as well as the impact it would have on the environment. The results gathered from this study align with that of previous research done into this topic in that constructing the tidal power plant provides more efficient and cheaper energy as well as producing less carbon dioxide emissions.

\section{Exploring the efficiency of clean energy allocation and generation in Indian regions}

\section{Amy Li ${ }^{1}$ and Eva Wu ${ }^{1}$}

\section{${ }^{1}$ Hillfield Strathallan College, Ontario, Canada}

India is experiencing significant growth in many aspects. As a result, energy consumption within the country has increased rapidly in the past decade. Achieving high energy efficiency is an essential part of long-term development for the country, given its relatively low GDP per capita. The objective of our research is to explore the necessity of optimizing the clean energy generation and allocations in India and finding possible directions to improve the energy efficiency. In our research, we have retrieved data from the Kaggle website that includes the estimated, generated, and consumed amounts for three types of clean energy (i.e., thermal, nuclear, and hydro). After processing the data, we noticed large differences between the amounts of estimated and actually generated energy and even higher discrepancy between the amounts of generated and consumed energy. Furthermore, large amounts of energy were distributed across the regions which we believe incurred high distribution costs. Based on these findings, we found there was room for improvements in the energy generation and allocations in India in terms of both ameliorating the estimation accuracy and reducing the distribution cost in order to support India's energy preservation.

\section{Pumped hydro stations an analysis into increasing the reliability and large-scale dependence on renewable energy sources}

\author{
Aveer Singh ${ }^{1}$ and Ana Dolghiu ${ }^{2}$ \\ ${ }^{1}$ Mentor College, Ontario, Canada \\ ${ }^{2}$ Hillfield Strathallan College, Ontario, Canada
}

With the world transitioning to use more renewable energy sources as opposed to traditional and environmentallydamaging fossil fuels, the issue of inconsistent clean energy production arises. Current renewable energy sources cannot supply the power grid with steady and consistent energy to meet demand. This study aims to analyze whether a hydro pumped storage station would solve the issue of renewable sources supplying inconsistent energy in Vancouver, British Columbia, Canada. The collected data focuses on the Greater Vancouver Area (GVA), however we seek to apply our findings on a larger scale, making any findings applicable to areas around the world with similar geographical characteristics to Vancouver. The hope is that by analyzing Vancouver's current and projected future energy consumption, as well as the Area Control Error (ACE) of their power grid, we can determine whether installing a pumped hydro station would increase the reliability of the large-scale use of renewable energy sources in Vancouver. Our findings suggest that Vancouver would definitely benefit from the installation of a hydro pumped station and that it would be the most affordable and most developed solution to the issue of fluctuating energy 
production from renewable sources. This paper's results provide a solid base to further research on the practical implementation of a hydro pumped station in Vancouver and in similar regions around the world with large geographical changes in elevation. Hydro pumped storage stations could revolutionize the reliability and large-scale dependence on renewable energy sources.

\section{Investigating the impact of geographic factors on access to clean energy in Indigenous communities across Canada}

\section{Ayesha Siddique ${ }^{1}$, Saima Siddique ${ }^{1}$, Brinly Yuen ${ }^{1}$, and Fakaiha Zaheed}

\section{${ }^{1}$ Glenview Park Secondary School, Ontario, Canada}

In an ideal and sustainable world, all citizens would have access to clean and affordable energy. However, in Canada, many Indigenous communities do not have such access. Inspired by the increasing awareness on issues and inequalities faced by Indigenous communities, as well as reconciliation efforts, our team decided to investigate how the location and remoteness of these communities affect their access to clean energy, specifically access to solar, wind, biomass and hydroelectric energy. To assess the situation, we found data for over 200 Indigenous reserves and their corresponding energy sources, as well as coordinate information, from Indigenous Clean Energy and The Atlas of Canada's Remote Communities Energy Database. We analyzed the data using Python's various public libraries, from numpy to geopandas, creating a variety of visualizations ranging from maps to boxand-whisker plots, in order to identify trends and correlations. From our results, we discovered some disparities in the total current clean energy generation and in the distribution of energy sources used by Indigenous communities. We concluded that remote Indigenous communities, especially in the north, have a disadvantage with regards to clean energy access.

\section{An investigation and comparison of the effectiveness and greenhouse gas emissions of traditional diesel-powered school buses and}

\section{electrical school buses}

Bella Lu ${ }^{1}$, Cyrus Ng${ }^{1}$, Jeremy Jiang ${ }^{1}$, and Jessica Heaton $^{1}$

\section{St. Michaels University School, British Columbia, Canada}

This paper focuses on our current diesel powered school bus program and ways to improve it. Rather than looking at the whole picture, we delved into each individual bus route and assessed its advantages and drawbacks. Some routes, as we discovered, were far from optimal. The most apparent solution would be to completely replace the diesel buses with electric ones; however, that ideal is not currently realistic. Thus, we looked into more probable alternatives. To accomplish this, we collected data on bus carbon emissions as well as how much students would emit if they were to drive themselves. Comparing these two variables, we found that certain routes can be dramatically improved.

\section{Renewable energy generation in remote communities}

\section{Cheryl Chen ${ }^{1}$, Anubha Joshi ${ }^{1}$, and Selina Ou ${ }^{1}$ \\ ${ }^{1}$ Earl of March Secondary School, Ontario, Canada}

Our aim was to determine the factors that influence clean energy generation in remote communities in Canada. To accomplish this, we used a dataset from the Government of Canada on renewable energy generation in remote communities that also included information like location, settlement type, community type, year-round road access, etc. We used Python and matplotlib to find direct correlations between individual variables and their renewable energy generation. Linear regression was used to compare the renewable energy disparity between Indigenous and nonIndigenous communities. Finally, we used mean shift to cluster the individual features and look at how combinations of variables affect renewable energy generation holistically. Our major findings were that wealth and population play a role in having high renewable energy generation in remote communities, and having year-round road access is also vital unless the community is a settlement community with its own independent grid. We concluded that the government should provide more infrastructure to Indigenous communities to boost renewable energy generation, and that they should 
provide incentives to commercial communities to make the switch.

\section{Investigating the correlation between investment in renewable energy and $\mathrm{CO}_{2}$ emissions}

\section{Cheung Tsz Hong', Chung Chun Wang', Leung Chun Long ${ }^{1}$, and Yip Yan Yu Julian ${ }^{1}$}

\section{Po Leung Kuk Choi Kai Yau School, Hong Kong}

This research project aims to assess the progress in achieving Sustainable Development Goal 7 and Goal 13 (SDG 7 , SDG 13) by nations around the world: to ensure access to affordable, reliable, sustainable and modern energy for all, and take urgent action to combat climate change and its impacts respectively. This is done by investment in research and development of renewable energy sources by governments, which could eventually replace burning of fossil fuels, hence slowing down the rate of climate change as well as providing more clean energy to the general public at an affordable price. As such, raw data such as investment patterns on renewable energy of countries and $\mathrm{CO}_{2}$ emission trends were downloaded, then by using python and SQL data were sorted and graphs were generated. In general, investment goes up every year, where although initially $\mathrm{CO}_{2}$ emission did go up, the rate of increase slowed down every year, eventually the amount of $\mathrm{CO}_{2}$ emission started to decrease.

\section{The hurdles of EV adoption: Simulating charging times using big data}

\section{Evan Skrukwa and Rahul Ravikumar ${ }^{1}$ \\ ${ }^{1}$ Westmount Charter School, Alberta, Canada}

Road transportation accounts for a significant portion of all harmful emissions. In order to reduce human activity which contributes to climate change, road transportation emissions must be addressed. Electric vehicles (EVs) have been proposed as a solution. According to consumers, charge times offered by current EVs pose a significant hurdle in widespread adoption. Since current EVs charge at a faster rate the more depleted they are, charging smaller amounts starting from lower percentage levels, and repeating this multiple times to cover the same range may be a solution to consumer expectations. Using population representative and randomized simulations of trips roughly 291 miles in road length in the US, as well as randomly varying how many charge points were available, a significant correlation between total charge time and amount of available charge points was not found. However, charge time did decrease slightly (12\%) and 100 simulation rolling standard deviation also decreased (52\%) when simulating current charge point infrastructure in the US, compared to no charge point infrastructure. Furthermore, trips that could not find at least 1 charge point to stop at, were classified as failed trips, and occurred at high rates with simulated charge points under 1,000 . With greater than 1,000 simulated charge points, the rate of failed trips became negligible, signifying the point of diminishing returns. The results suggest that in the current state, charge times are no more of a hurdle than price and range of EVs. Greater spending and development in charge point infrastructure past what the US is already equipped with is not expected to reduce average charge times significantly.

\section{Exploring economic factors in clean energy adoption worldwide}

\section{Hanz Nathan Qua Po}

\section{Francis Libermann Catholic High School, Ontario, Canada}

Climate change has been and is still a major problem throughout the world. Some of the top contributors to $\mathrm{CO}_{2}$ emissions are coal, oil, and gas, making the switch to clean energy an obvious and necessary one. This study investigated how economic factors influence the adoption of clean energy across the world, by looking at Gross Domestic Product (GDP) per capita, oil production per capita, and Human Development Index (HDI) values. This information was then compared to the proportion of energy from low-carbon sources in each country. Pearson correlation coefficients and $R^{2}$ values were examined in conjunction with polynomial regression analysis, primarily with Python. Since GDP per capita is a reliable indicator of economic strength, it was the first factor considered in the analysis, in addition to HDI, which takes into account several economic and developmental factors, offering a different perspective of a country's success. Finally, 
oil production per capita was also chosen, because it was hypothesized that countries which benefit economically from oil production may be less inclined to adopt clean energy. Based on these data, results from the analysis indicated that countries with a higher GDP per capita and HDI were more likely to adopt clean energy. Countries that produce more oil are less likely to adopt clean energy, however, there are numerous exceptions. Therefore, economic factors play a significant role in clean energy adoption, but there may be other contributing factors. Future studies may look into exactly what other factors affect it.

\section{The variation of renewable energy in the context of global economic and social well- being}

\section{Ziheng Wei ${ }^{1}$, Zirui Wei ${ }^{1}$, and Jason Huang ${ }^{1}$ \\ ${ }^{1}$ Crescent School, Ontario, Canada}

Reliable energy sources are essential to the operation and advancement of society. As renewable energy (RE) rapidly integrates into society to meet the growing demand for affordable and clean energy (UN's Sustainable Development Goals 7), it is crucial to analyze the merits and flaws of RE. In order to assess the economic, environmental, and social aspects of SDG 7, this paper evaluates the correlation and causality between RE, economy, and environmental indicators. We gathered data from diverse sources, including The Center for Climate and Energy Solutions, NASA GISS, and Our World in Data, for our RE, temperature, $\mathrm{CO}_{2}$ emissions and GDP data. Tentatively, we can conclude that RE has limited effects on the global economy but has considerable implications on social and ecological wellbeing (both positive and negative) according to the trends of the past two decades. These results offer insight into the viability of RE as a vehicle to achieve SDG 7.

\section{A proposal for clean energy in Red Deer, Alberta based off an examination into the viability of specific renewable energy solutions}

\author{
Isaac Bahler ${ }^{1}$ and Samantha Chong ${ }^{1}$ \\ ${ }^{1}$ Lindsay Thurber Composite High School, Alberta, Canada
}

The objective of this report is to analyze a variety of renewable energy options specifically focused towards Red Deer, Alberta in order to demonstrate that climate change can best be tackled when individualized solutions are applied to the problem. Our report used data provided by the Canadian government to analyze key factors such as: socioeconomic status, unique geography, prior industry infrastructure, and existing renewable resources. All data was analyzed using Google Sheets. Google Sheets was also used to construct visuals. With those factors in mind a costbenefit analysis accounting for carbon emission was applied to solar, hydroelectric, wind, nuclear, and geothermal. Using this method wind and solar were determined to be the most viable. Ultimately, the proposal suggested that implementing wind and solar over the next 10 years to cover $60 \%$ of Red Deer's power needs along with supplemental geothermal power Alberta was most reasonable. The total cost of the project was calculated at $\mathbf{2 3 3 . 5}$ million dollars and a brief analysis was conducted to recommend how funding should be procured. Additionally, research indicated that the Joffre Chemical plant, Red Deer's largest manufacturer, could have its power needs met with a small nuclear reactor. Carbon Sequestration is recommended to reverse some of Alberta's long term ecological damage. The argument that an individualized approach to addressing climate change is more efficient is upheld upon our scrutiny. Similar approaches can be used throughout Canada and the world as part of a larger climate solution.

\section{The effects of implementing a carbon tax on greenhouse gas emissions}

\section{Jonathan Barazzutti' ${ }^{1}$, Paul Milan Diaz ${ }^{1}$, and William Zhou ${ }^{1}$}

\section{' Westmount Charter School, Calgary, Alberta}

Globally, carbon emissions are projected to cause a $1.1^{\circ} \mathrm{C}$ to a $5.4^{\circ} \mathrm{C}$ increase in temperatures from now to 2100. Current attempts to tackle the climate shift include market-based mechanisms ranging from varying levels of carbon taxes to emissions trading. Using multivariate time series regression, this paper analyzes the differing trends between nations that have implemented a carbon policy relative to nations that have not, and how those have 
affected their carbon emissions levels within 1 and 5 years of implementation. None of our model specifications reveal a statistically significant relationship of any kind between an increased carbon tax and carbon emissions. This marked lack of relation between carbon tax policy implementation and carbon emission decreases points to a need to reexamine the way we implement policy to reduce carbon in our world.

\section{A multivariate approach to optimizing solar power production in Ontario}

\section{Vikas Nibhanupudi}

\section{John McCrae Secondary School, Ontario, Canada}

Solar power is a renewable, but underused, energy source. Although solar power production has become more affordable in recent years, critics argue that climate variations make it unreliable. This study attempts to prove that careful consideration of weather conditions in a region can assist in maximizing solar power production. A dataset containing weather and solar irradiance data for a year was used to perform univariate and multivariate regression analysis. It was found that air temperature, cloud opacity, and relative humidity had the greatest effect on solar power production. Using the univariate regression analyses, optimal ranges for each of these highly-correlated weather conditions were determined. These findings were applied to locate three Ontario cities with the ideal weather conditions for solar power production. The findings in this study demonstrate how weather conditions significantly impact a region's ability to produce solar power. This study is unique because it explores an inexpensive and relatively unexamined method of increasing solar power production in Ontario. By paying special attention to weather conditions when building solar power plants, governments can maximize their country's solar power production at no additional cost.

\section{Clean energy and a country's economic investment}

\section{Adam Omarali ${ }^{1}$, Haoyang Liư ${ }^{1}$, and Tian Yi Yang ${ }^{1}$ \\ ${ }^{1}$ Crescent School, Ontario, Canada}

Rising $\mathrm{CO}_{2}$ emissions pose threats to the world's ability to self-regulate, but recent advancements in clean energy hope to reduce the amount of fossil fuel production by providing better alternatives. This paper assesses the current state of clean energy while identifying correlations that can influence our next steps in clean energy. Such correlations consist of fossil-generated energy production and GDP with coefficient of correlation $\left(R^{2}\right)$ being 0.9891 , fossil fuel production and fossil fuel consumption $\left(R^{2}=0.9744\right)$, fossil-generated energy production and clean energy production $\left(R^{2}=0.9998\right)$. Overall, trends in development and energy production had shown statistical evidence to be strongly correlated in terms of the sample data that was gathered and analyzed.

\section{Legitimacy of electric vehicles to be the greener alternative}

\section{Tanmay Thakur}

\section{Ryan International School Ghaziabad, Uttar Pradesh, India}

The aim of study was to analyze the current available evidence and add a different perspective to the issue of electric vehicles. Electric vehicles are the future of the automobile industry and the most widely accepted reason is that it is considered a greener vehicle as compared to an internal combustion (IC) vehicle. The finding in the paper suggests that it is not necessarily the case. The situation varies from country to country and a general overview of the information suggests that in most circumstances an electric vehicle is likely to add more or almost the same carbon footprints as an IC vehicle. Some solutions are mentioned that suggest ways of helping the automobile industry become greener.

\section{Analyzing the socioeconomic distribution of solar rooftop adoption in California}

Tenzin Migmar ${ }^{1}$, Minkila Bara ${ }^{1}$, and Bhavini Patel ${ }^{1}$

\section{${ }^{1}$ Runnymede Collegiate Institute, Ontario, Canada}

Over recent years, rooftop photovoltaic systems have experienced growth in popularity and use. For solar energy to maximize its outreach, it must be easily accessible to all. In this paper, we investigate the intertwined relationships between socioeconomic factors to understand how sectors of the populace have responded to rooftop photovoltaic 
adoption. Using an open-access database, DeepSolar, we apply data analytic techniques and gradient boosting algorithms, to examine and visualize trends in the uptake of rooftop photovoltaic as well as forecast the solar energy transition on granular populations. Our preliminary analysis examines the correlation between generic socioeconomic indicators and siloed isolated subgroups using Pearson's correlation coefficient and Ordinary Least Squares regression. The second component of this study explores the potential for forecasting solar deployment density using only socioeconomic features. We trained a gradient boosting regressor model to predict the number of solar installations per thousand households within census tracts and obtained an R2 of 0.56 after hyperparameter tuning. To understand the extent each feature contributes to solar adoption, we retrieved the feature importance of each variable revealing their influence on predictions. Through coalescing this study's results with the implementation of the gradient boosting model, policymakers can identify and address the most pressing challenges to solar energy uptake as well as curate targeted interventions to alleviate energy poverty for a more equitable and cleaner future.

\section{The ability of a country to produce solar power}

Shirley Yu

\section{Collingwood School, Vancouver, British Columbia}

With the ever-increasing dependence on energy consumption, it is vital that we pursue renewable energy. In the past couple of decades, "the price of solar modules declined from $\$ 106$ to $\$ 0.38$ per watt. A decline of $99.6 \% "$. Solar power is now the cheapest electricity in history and the barriers to make use of it are decreasing. Data from 48 countries from 2000 to 2019 were collected for this study. Seven socioeconomic factors were measured. The influences of geographic factors like longitude, latitude, climate, etc were represented by the total potential solar energy generation. Various graphs of each variable and calculations of Pearson correlations, VIFs, random forest feature importance, and a multivariate regression line were assessed using Python. The regression results indicated that while geographic factors affect a country's solar energy production, there are many correlated socioeconomic factors - with GDP and internet usage being the two most important - that programs and government regulations can manipulate to increase solar power production. Even considering the limitations of geographic factors, current solar power production is far from its potential output.

\section{Analyzing the impact of core national indicators on clean energy production}

\section{Sanjay Jayaram', Zuri Zheng ${ }^{1}$, Rory Jennings ${ }^{1}$, Himanshu Sangale ${ }^{1}$}

\section{${ }^{1}$ Westmount Charter School, Alberta, Canada}

With the growing threat of climate change, efforts to reduce carbon emissions through switching to green energy have come to the forefront of public discussion. Fossil fuel use for energy production is a significant contributor to carbon emissions, and a transition to cleaner methods such as wind, solar, hydro electric, and geothermal power is needed. However, the relative success of this switch has varied between countries. The purpose of this study is to determine what factors are the strongest indicators of how much clean energy a country is using relative to its fossil fuel use. Various socioeconomic factors, as well as geographical factors, are considered. The data shows that colder, wealthier, more developed nations tend to use more clean energy relative to their fossil fuel usage, however this correlation is regional, with it being most true in Europe. Future efforts to continue increasing usage of clean energy should consider how successful countries have been up until now, and the differences between regional success.

\section{The leapfrogging solution to global renewable energy and access to energy}

\section{Sam Hosseini-Moghaddam¹, Branav Kumar Gnanamoorthy ${ }^{1}$, Harry Cheng ${ }^{1}$, and Thomas Liang ${ }^{1}$}

\section{${ }^{1}$ University of Toronto School, Ontario, Canada}

Low renewable energy consumption and access to electricity have become two of the most important issues of our time. One proposed solution to both problems has been energy leapfrogging, or skipping directly to small- 
scale renewable energy sources in developing countries. We set out to determine energy leapfrogging's potential for improving renewable energy consumption and access to electricity in developing countries. We applied regression models, and utilized significance tests in order to quantify the correlation between the variables of Gross Domestic Product (GDP) and renewable energy consumption (\% total energy consumption). Results show there was no statistically significant correlation between the two. In addition, global and local spatial autocorrelation analysis were conducted. Here we found that geographic clusters had similar values for both renewable energy and GDP. A second dataset was used to project consumption into the future in non-OECD countries and compare this to the growth of OECD (Organization for Economic Co-operation and Development) countries during their development stage. We found that in their current trajectory, developing non-OECD countries are following the same path as OECD countries. We conclude that energy leapfrogging shows potential as a solution to low renewable integration and access to energy.

\section{The economics of implementing solar PV globally}

\section{Sydney Choe', Madison Choe ${ }^{1}$, Kelley Liang ${ }^{1}$, and Mustafa Qureshi ${ }^{1}$}

${ }^{1}$ Holy Trinity School, Ontario, Canada

As the ramifications of climate change are magnified, action must be taken to mitigate the primary contributor of $\mathrm{CO}_{2}$ emissions in many developed countries: fossil fuels used for energy. Renewable energy is often regarded as one of the most impactful viable solutions against the climate crisis. This paper compares the growth of the solar energy industry versus costs, using data from Our World in Data's Renewable Energy dataset. We will use linear regression to compare costs and the growth of the solar energy industry, in an attempt to formulate a casual understanding of the two variables.

\section{The impact of manufacturing emissions in the automobile industry on global sustainability} Mohammed Talha Tahseen', Rafat Hossain',

\section{Zuhair Qureshi ${ }^{1}$, and Dennis Lu ${ }^{1}$ \\ ${ }^{1}$ Victoria Park Collegiate Institute, Ontario, Canada}

As income rises worldwide and people gain access to modern transportation, the negative external cost is often unrealized. The effect of inefficient manufacturing methods and rising fuel prices for cars harm the climate and play a significant role in global warming, accounting for over $10 \%$ of all fossil fuel emissions. Our research found that electric vehicles have an advantage over gas vehicles due to a more prominent public call for immediate action towards reducing carbon emissions, lower maintenance costs, and lower charging costs. However, manufacturing methods for vehicles have not changed and continue to contribute a large portion of the carbon footprint made by the automobile industry. We created multiple visual representations of data collected from various digital sources to conclude that, although electric cars are the future of transportation, the methods of manufacturing electric cars have to change in order to make carbon neutrality across the entire automobile industry a more plausible reality. Our solution for a carbon-neutral manufacturing process begins by examining the factory itself and where it gets its energy from. We found from resources that the majority of the factory's electricity is spent on HVAC systems, paint, and ventilation. Thus, finding a renewable energy source would be the priority, which would then be followed by replacing existing systems with more efficient ones. We propose that solar energy is the most efficient and economically viable option for the long-term renewable energy source.

\section{Canadian energy inequity: Affordable and clean energy in remote Indigenous communities}

\section{Rasheed Ahmad ${ }^{1}$ and Victoria Moore ${ }^{1}$}

${ }^{1}$ Lorne Park Secondary School, Ontario, Canada

Much of the conversation around affordable and clean energy centers around the people who already have their energy needs met. In this paper, we will examine the energy data for Indigenous Canadian settlements. Specifically, those which are not connected to major electrical grids or pipelines, that are not accessible by roads year-round, and are not fly-ins. This information is publicly accessible through the 
Government of Canada's open data resource, due to the small sample size of these communities, we were able to go through this data without needing complex programs, everything was done by hand. We observed discrepancies in the performance of their fossil fuel and renewable energy sources compared to national Canadian averages. It was found that the percentage of renewable energy in these settlements was greater than the national average, however, this data was misleading because the total amount of energy in the settlements was so comparatively small, as the average Canadian uses more energy than those living in these communities. This brings up new concerns about the reduced energy in these communities negatively affecting the quality of life for Indigenous people. This project is very important because it focuses on the people who are energy insecure, rather than those who need to start using cleaner energy. Improving quality of life through access to clean energy is a vital first step in the fight against climate change, and we should help the energy insecure first because that solution ensures that the highest amount of people have sufficient energy.

\section{A treatise on the impacts of the transportation sector on the environment}

Rory Kellway' ${ }^{1}$, Luca Pizzuti ${ }^{1}$, Patrick Ross ${ }^{1}$, and
Patrick Fahey ${ }^{1}$

${ }^{1}$ Neil McNeil Catholic High School, Ontario, Canada

The increase in concern regarding global warming has started an initiative to keep track of and reduce global emissions while gradually converting to clean, renewable energy. The objective of this study was to assess correlations between city emissions and their transportation systems. We selected these factors because transportation is a vital part of community and individual movement. We acquired our data from various different sources such as raw data sets, previous research, and government emission reports. Many different methods were used to analyze our data. For the raw data sets using code we compiled noteworthy correlations between emissions and transportation systems. The findings showed that a city's size and population was proportional to its transportation emissions. Overall, effective transportation systems will be increasingly more important for the future. Poor infrastructure and design may lead to greater emissions and we call for city planners to consider climate and environmental impacts in their design and redesign.

\section{Multivariate analysis of consumer-specific factors affecting AFV adoption in the United States}

Keshav Ganapathy Raman¹, Gayathri Aravindan², Marcus Yim³, and Nikhil Devisetty ${ }^{1}$

${ }^{1}$ Interlake High School, Washington, United States of America

${ }^{2}$ Richard Montgomery High School, Maryland, United States of America

${ }^{3}$ Belleveue High School, Washington, United States of America

Gasoline-powered cars add to a significant amount of emissions released into the earth's atmosphere every year. AFVs have been identified as an excellent way to decrease this number. The primary goal of this investigation is to analyze the association between specific consumer variables and AFV adoption. Previously established research on EV adoption in Hawaii lays the foundation for this paper. Its discussion of consumer characteristics influences the adoption factors considered in this exploration. The dataset used was from a study organized by the FHA regarding general American travel patterns. Analysis was conducted using Python on the Jupyter Notebook IDE, with libraries including Pandas, Scikit-learn, and Seaborn. Additionally, the chi-squared and Cramer's V statistical tests were used to evaluate the correlation between various factors. These results had a few correlations, with the most relatively weak, but based on some premise. Factors like education and household income were determined to correlate with the adoption of said vehicles. Many associations arise from systematic issues. This research can be the basis for the adoption of AFVs, and researchers in the future can build upon such foundations, following the methodology established in this study.

\section{Seeking steps toward sustainability by contrasting Texas and California}

Richard Li', Tianyi Xu'1, Charlie Meng' ${ }^{1}$, and Ricky Shao ${ }^{1}$ 


\section{${ }^{1}$ Hillfield Strathallan College, Ontario, Canada}

In a world that is becoming increasingly dependent on energy usage while energy pollution is becoming a more and more of a serious problem, it is crucial for the world to gain a better understanding on how to improve the issue. By changing the sources and usage of energy, however, we can work towards a more sustainable future. Hence, our aim is to contrast Texas and California's energy usage and consumption by identifying factors that make one state better in energy usage than the other. We analyzed the different energy resources (mostly fossil fuels and renewable energy) that each state uses and as well the usage of these energy through the perspectives of residential, commercial, industrial, and transportation.

\section{Energy consumption and impact in the healthcare sector and the usage of renewable energy in the future of healthcare}

\section{Kushi Jakati ${ }^{1}$ and Bobby Bhandari ${ }^{1}$}

${ }^{1}$ The Early College at Guilford, North Carolina, United States of America

Due to the heavy energy maintenance of hospitals, hospital energy management has become a prominent topic in the discussion of sustainable energy. However, lack of available and consistent data outlining the breakdown of energy consumption by the US healthcare sector has made it difficult for the healthcare infrastructure to both gauge the appropriate sustainable energy practices as well as assess the current state of the US healthcare energy sector. Thus, the objective of this research is to investigate both the energy composition and the sustainability of the US healthcare industry over the years, as well as provide more insight into the potential energy objectives the US healthcare sector can pursue in the future. Data for this research was analyzed through Google Sheets, Microsoft Excel, Python libraries, and Tableau. The subsequent analysis assessed the following of the US healthcare sector: major fuels' growth and decline from 2003 to 2012; green-building incentives in the 21st century; energy consumption and expenditure in relation to the averages of the commercial industry; energy end uses of large hospitals in 2003. Results from the analysis demonstrate the following characteristics of the US healthcare system: a heavy reliance on natural gas and fuel oil, high energy intensity and inefficiency respectively in hospital activity and equipment, and a large gap in nonrenewable and renewable energy use. These results suggest a need for hospitals to turn towards more sustainable energy practices in the future specifically, towards an increased dependency on renewable energy in light of recent renewable energy projections.

\section{The effect of nuclear power on electricity rates in Alberta, Canada}

\section{Rong Liu}

Sir John A. Macdonald Collegiate Institute, Ontario, Canada

As Alberta is determined to phase-out coal-fired generation and adopt more non-emitting generation, nuclear power has become a potential choice as a clean source of generation. This study investigates the possible impact of nuclear power on Alberta's electricity rates by examining factors that may be correlated with Alberta's electricity rates. Open-source data were collected to conduct this study and the method of linear regression was used to model the electricity rates. Single regression models were used to determine factors that correlates with Alberta's electricity rates, and multiple regression models were made using factors that show correlations with the electricity rates. The results revealed that total electricity generation, renewable generation, total installed capacity, and oil price have the strongest correlations with electricity rates. The study did not find correlations between carbon emissions and carbon pricing charges with the electricity rates. From the predictions of the regression models, it was found that adopting nuclear power in Alberta would result in lower electricity rates than not adopting it. This suggests that adopting a higher carbon tax will not increase Alberta's electricity rates. Moreover, economic factors may influence Alberta's electricity rates more than technical factors. We recommend more research could be done in investigating the impact of economic factors on electricity rates in Alberta and Canada.

\section{Analyze decline of solar energy adoption in North Carolina and recommended growth path}

Rohith Madhuker 
Enloe High School, North Carolina, United States of America

Affordable and Clean Energy is the seventh of UNESCO Sustainable Development goals. The United States (US) has an excellent opportunity for solar power growth as the cost for solar has dropped by more than $20 \%$ in the past five years, and policies are becoming more favorable based on consumer surveys. Despite the exponential growth of solar adoption in the US, North Carolina's (NC) Clean Energy Goal to attain carbon neutrality by 2050 is at risk as the state's solar growth has dropped from second to thirteenth place and overall capacity from second to fourth place in two years. Datasets were gathered to analyze the growth, compare states which have recently performed well, and document the key contributing factors for the decline of NC's adoption in Solar Energy. Python libraries such as pandas and seaborn were used to draw heat maps to find the correlation between these factors. The factors which impacted solar energy adoption the most were analyzed using a linear regression model through machine learning functions. Based on the predicted models, the following are the recommendations to get NC on the growth path for solar adoption: (1) make Home Owner Association policies favorable by passing the North Carolina HB842 bill; (2) improve net metering rates to reduce cost for consumers; and (3) prevent further decline of growth by extending Federal tax exemption beyond 2024 . We recommend future researchers employ similar methods to other regions.

\section{How does climate change have an impact on the effectiveness of hydropower in Brazil?}

\section{Jessica Li ${ }^{1}$, Rachna Venkatesh ${ }^{1}$, Shahd Alsafadi ${ }^{1}$, and Somana Debnath ${ }^{1}$}

\section{${ }^{1}$ Glenforest Secondary School, Ontario, Canada}

This paper investigates the effect of climate change on the efficacy of hydropower generation in Brazil. This includes factors such as temperature, precipitation, and water withdrawals. Using data sets of annual mean temperatures, average monthly precipitation, annual freshwater withdrawals, and hydroelectricity generation in Brazil, the correlations were investigated. We used the Jupyter software and Google Colab with the Python 3 program, along with the libraries Pandas and Seaborn to create data visualizations and conduct statistical tests during analysis. Findings showed each of these factors were correlated with hydropower generation: temperature being a strong factor in this case, precipitation being a weak factor, and freshwater withdrawals having a very high correlation with hydropower generation. The role of hydropower in Brazil's energy production is arguably essential for the country's future, when the effects of climate change will be prevalent. Moreover, hydropower generation has both advantages and disadvantages, and therefore, the technological, social, economic, and environmental aspects of hydropower are critically considered in this report to ensure that its implementation results in the most beneficial solution to tackle climate change.

\section{Investigating renewable energy price, investments, and technological innovation to find a solution for the climate crisis}

\section{John Brennan'1 Michael Perry ${ }^{1}$, Frank Pasztor ${ }^{1}$, and Sheldon Broughton ${ }^{1}$}

${ }^{1}$ Neil McNeil Catholic High School, Ontario, Canada

Increasing investments in renewable energy will be essential for improving technology innovation and the growth of renewable energy usage and market share. Investments in the newer forms of renewable energy technologies in the areas of solar and wind are strong but these only contain small slivers of the overall energy market. The largest share of the renewal energy share of the market belongs to hydro power. Investment and innovation with hydro power appears to have been flat for some time. We discovered what is taking place with the main sources of renewable energy by analyzing its share of the energy market. Fossil Fuels continue to dominate the energy market in spite of their negative effects on the environment and human health. On the other hand, renewable energy has captured a significant market share. This share does not appear to be growing. We also evaluated the main types of renewable energy: hydro, solar, and wind. Hydro power has the largest share, followed by solar and wind. Prices of renewable energy have significantly fallen while volumes of usage have risen. Investments and patents are relatively stable. Therefore, we recommend improved investment, technological innovation, and expansion of the availability of renewable energy. Prices will continue to fall 
and volumes to increase further, growing the renewables share of the energy market.

\section{The impact of various socioeconomic factors on the carbon emissions of a country}

\section{Jacob Guglielmin1, Enzo Mutiso1, and Faraz Hosseinian-Tehrani ${ }^{1}$}

\section{${ }^{1}$ Westmount Charter School, Alberta, Canada}

The effects of climate change have had a profound impact on people around the world. The global surface temperature and global upper ocean are warmer than ever, and carbon dioxide $\left(\mathrm{CO}_{2}\right)$ emissions are at an all-time high. There is an urgent need for understanding and addressing the effects of climate change to avoid irreversible damage to our planet. In order to provide insight into the ways that lifestyle may influence carbon dioxide emissions, data were collected on five key socioeconomic factors across countries and compared to that country's $\mathrm{CO}_{2}$ emissions. Regression analyses were performed between each socioeconomic factor and that country's $\mathrm{CO}_{2}$ emissions, and the results were evaluated based on their coefficient of determination as well as their significance. This study showed $\mathrm{CO}_{2}$ emissions exhibited a significant positive correlation with GDP per capita, education index, and life expectancy, and a significant negative correlation with poverty rate. Population density did not exhibit any significant relationship to $\mathrm{CO}_{2}$ emissions within a country. These results suggest there is a strong relationship between the quality of life and the $\mathrm{CO}_{2}$ emissions of a country. It is apparent that in order to have the greatest impact on climate change worldwide, solutions should focus heavily on highly developed countries. In addition, less developed countries should consider working climate change mitigation strategies into their development plans in order to maintain their low levels of $\mathrm{CO}_{2}$ emissions.

\section{Examining the United Kingdom's usage of hydrogen storage}

Matthew Engelman'1, Ryan Saloff', Marcus Thoen, and Cameron Birkby ${ }^{1}$

${ }^{1}$ Westmount Charter School, Alberta, Canada
The purpose of this study is to simulate the implementation of the United Kingdom's Hydrogen Strategy from 2030 to 2050 to determine if green hydrogen is a viable longterm source of energy not only for the UK, but on a global scale. Green hydrogen is a type of hydrogen storage where renewable energy is used to extract pure hydrogen from water molecules. The hydrogen is later combusted to be used as energy. This will be compared against blue hydrogen, a less environmentally friendly but cheaper alternative which uses natural gas to extract the hydrogen. Using data collected from various sources and statistical modelling, the costs and greenhouse gas emissions of green hydrogen, blue hydrogen, and natural gas will be compared with one another, as if each one was the subject of the UK Hydrogen Strategy. After calculations, it is made clear that natural gas is the most cost-effective form of energy production in the UK, at least until 2050. However, replacing 5GW of natural gas production with green hydrogen for 20 years is estimated to restrain 360 million tonnes of $\mathrm{CO}_{2}$ eq from entering the atmosphere. Combine that with the fact that green hydrogen is eventually projected to become cheaper than natural gas, and it is a compelling option. Other regions across the world may have a harder time implementing hydrogen storage into their economies due to limitations in infrastructure, but with enough commitment it can be beneficial long-term.

\section{Multiple factor regression analysis of vegetation changes and land degradation in drylands}

\section{Maria Chzhen}

\section{Westdale Secondary School, Ontario, Canada}

Desertification, or the reduction in vegetation, is a form of land degradation in arid, semi-arid, and dry sub-humid areas, collectively known as drylands. According to National Geographic, desertification is a serious environmental concern that may affect about 2 billion people living on the drylands and could displace an estimated 50 million people by 2030 . In this report, longitudinal research using secondary data was conducted. The purpose of the study is to quantify the effect of various factors, including drought, precipitation, $\mathrm{CO}_{2}$ emissions, forest area, and electrical energy consumption, on the vegetation cover of multiple regions using multiple 
factor regression and identify measures that can be taken to increase the vegetation cover. Geospatial data was extracted from the Advanced Very High Resolution Radiometer (AVHRR), and multiple statistical techniques were employed. The effect of each factor, including drought, precipitation, $\mathrm{CO}_{2}$ emissions, forest area, and electrical energy consumption, on land degradation and vegetation in regions around the world from 1995 to 2015 is quantified using multiple factor regression analysis and graphed with linear and asymptotic (sigmoid) curves and prediction intervals. Electrical energy consumption was found to be the most impactful factor.

\section{Electric vehicle buying trend}

Jane Nguyen

Charlottetown Rural High School, Prince Edward Island, Canada

The United Nations has emphasized the need to "enhance international cooperation to facilitate access to clean energy research and technology" in Target 7 within the 2030 Agenda for Sustainable Development. Therefore, this article explores electric vehicle buying trends using new motor vehicle registrations. The study also compares fuel and electricity price changes based on Consumer Price Index and costs. Data spanning from 2011 to 2020 was gathered for Prince Edward Island and analyzed using multiple regression models. By utilizing Google Sheets, Microsoft Access, and Python libraries, the tendency of purchasing electric vs gas vehicles in the market was studied regarding vehicle registrations and how energy sources' prices, namely fuel and electricity, were affected.

\section{How geographical factors affect production and accessibility of clean and affordable energy}

\section{Murede Adetiba ${ }^{1}$ and Katrina Zamberg ${ }^{2}$}

\section{St. Aloysius Gonzaga Secondary School, Ontario, Canada \\ ${ }^{2}$ Lawrence Park Collegiate Institute, Ontario, Canada}

Renewable energy has become considerably important considering the implications it has on the environment. It has become a priority for many to find sustainable ways to safely produce energy. This study assesses the worldwide access to electricity in rural areas, the worldwide usage of oil, the daily production of crude oil in Alberta, Canada, the crude oil and crude bitumen battery monthly flaring, venting and production data in Alberta, Canada and the global hydro power generated. The aim of this project was to assess whether there was a correlation between geographic location and production and accessibility of energy.

\section{Investigating the correlations between international wealth inequalities and renewable energy}

\section{Jadelyn Tran¹, Favour Atewologun¹, Shawn Wang1, and Raymond Lin ${ }^{1}$}

\section{${ }^{1}$ Webber Academy, Alberta, Canada}

Access to renewable energy is becoming increasingly important in the face of climate change, pollution, and global warming. However, this switch may be challenging for disadvantaged groups, such as those with a low socioeconomic status. In this study, we compared the socioeconomic status of various countries to their generation, production and investment in various forms of renewable energy to see if there was any sort of correlation. Determinants of such socioeconomic statuses included the Human Development Index (HDI), which measures quality of life, and the Gini Index, which measures income inequality. Python and R were used as tools to run inferential statistics, plot graphs, and regression lines. The overall low $p$-values and high $\mathrm{R}$-values of these results indicated statistically significant correlations between the chosen responding variables and energy access/ production. Most often, we observed upward trends in the Gini Indices with increased focus on clean energy. On the contrary, the same increase of clean energy led to lower HDIs. There was often a higher correlation with HDI than with Gini Index, which shows that standard of living is more affected by changes in renewable energy than income inequality. This gives an idea of how the world can set a target to improve overall quality of life while still maximizing renewable energy access.

\section{The correlation between country development}




\section{level and renewable energy consumption}

Karen Zhang1, Nicole Wong ${ }^{1}$, Archie Shou ${ }^{1}$, and Anika Thayaparen ${ }^{1}$

${ }^{1}$ University of Toronto Schools, Ontario, Canada

The global transition to renewable energy plays a pivotal role in fighting climate change. To determine which factors drive countries to consume more renewable energy, we examined the correlation between countries' renewable energy consumption per capita and its development level, measured by GDP per capita and Human Development Index scores. We found that there is a significant positive correlation between development level and renewable energy consumption. However, the correlation was weak as development level only explained around $25 \%$ of the variance in renewable energy consumption. Moreover, our analyses suggest more developed countries do not proportionally use more renewable energy than fossil fuels. Other factors may influence countries' renewable energy consumption. Overall, there is still a need for more progress to promote the shift towards a green future.

\section{A predictive model of energy efficiency for hydroelectric dams in California from 2015 to 2020}

\section{Kelly Hu${ }^{1}$, Jasmine Gau${ }^{1}$, Yann Chan¹, Daniel Scuba ${ }^{1}$ \\ ${ }^{1}$ Torrey Pines High School, California, United States of America}

There have been increasing efforts to maximize our use of clean energy to generate less pollution which adds greenhouse gases to the atmosphere. One of these clean energy methods is the use of hydroelectric power, which takes the natural flow of moving water to generate electricity. California is one of the significant states using hydroelectric power in the United States, with 274 hydroelectric facilities, generating $11 \%$ of its generation profile. However, hydroelectric power has its disadvantages. For instance, hydropower destroys many ecosystems because of its large facilities and can negatively impact water quality in areas. Thus, it is important to only build hydropower plants in areas where their efficiency can be maximized, reducing environmental damage. Using data collected from the National Centers for Environmental Information and the California Energy Commission, we generated a mathematical model using multivariable linear regression. Through our research, we discovered that the three main factors impacting the efficiency of hydroelectric dams are the amount of precipitation, the temperature in the area, and the slope the facility is built on. In this way, governments and private corporations intending to build hydropower plants can monitor the precipitation, temperature, and difference in the highest and lowest election in the area to find the optimal area to build. This may result in fewer power plants built as each plant could produce a high amount of energy and reduce environmental damage.

\section{Utilizing solar energy to design a sustainable house in Cape Town, South Africa}

\section{Keira Duggan¹, Isabella Golda1', Gabrielle Murray",} and Isabella Stringer ${ }^{1}$

\section{${ }^{1}$ Hillfield Strathallan College, Ontario, Canada}

South Africa is one of the world's leaders in coal production and is extremely reliant on this energy source, for which they lack the appropriate infrastructure to adequately distribute across the country. However, South Africa also has one of the highest potentials for clean energy implementation. Capitalizing on this capacity for renewable energy at an individual level, a three-person home was designed for living in Cape Town, South Africa that would provide each household with reliable, affordable, and sustainable energy through photovoltaic solar panels. The design of the house also uses renewable materials that will effectively reduce energy consumption per capita. This concept will allow South Africa to stay within the $2^{\circ} \mathrm{C}$ target of the Paris Agreement, a trajectory to which they are not currently adhering. While they aim to decrease greenhouse gas emissions over the next decade, South Africa's targets are not aggressive enough to achieve the necessary change. However, by relying on more sustainable energy sources and adjusting daily lifestyles, South Africans can become the driving force behind the adjustments the country must make.

\section{Climate change}




\section{Ennoj Haran}

\section{Sinclair Secondary School, Ontario, Canada}

The world has changed substantially with the industrial revolution and now the digital age. Many things such as quality of life and life expectancy have improved, but there have been detrimental impacts to climate and the environment. Our home is the earth. But, it is not just us that occupies the earth, there are other organisms, species, things that live too. We share the earth with others, is an overall statement to state. But, we have to take care of the earth, our home, is our responsibility, like a house in a city, the person owning that property is responsible for their own cleaning and managing their house. Society has a responsibility to care and maintain the planet, not harm existing ecological systems, and sustain life long-term. However, not enough is being done to protect the earth. Rather we are harming it. A major problem has occurred in the world, it is destroying plants and animals, causing natural disasters, etc. Who might you think started this? If you guess humans, yes, you are right. It is us. We are releasing many substances out into the world, which causes/ triggers a worldwide problem, called climate change.

\section{Statistical analysis of universal access to and share in global mix of clean energy}

\section{Mandi Jin \\ Western Canada High School, Alberta, Canada}

The first goal in Sustainable Development Goals 7 is that by 2030 , the world should ensure universal access to affordable, reliable, and modern energy services. However, the current situation is not that optimistic. Therefore, it is critical to switch to clean energy urgently. In this study, we will focus on three sources of energy: hydropower, solar, and wind. We analyze various factors such as race, geographical location, and socioeconomic level in getting access to clean energy among different countries, and how the total share of these three sources in the global energy mix changed over time in the world and to predict the total share in the future. 